Article

\title{
Improvements of Motor Performances in the Drosophila LRRK2 Loss-of-Function Model of Parkinson's Disease: Effects of Dialyzed Leucocyte Extracts from Human Serum
}

\author{
Andrea Diana ${ }^{1, *(\mathbb{D}, \text { Maria Collu }}{ }^{1}$, Maria Antonietta Casu ${ }^{2} \mathbb{D}$, Ignazia Mocci $^{2}{ }^{\mathbb{D}}$, \\ Miguel Aguilar-Santelises ${ }^{3}$ and Maria Dolores Setzu ${ }^{1, *}$ \\ 1 Department of Biomedical Sciences, University of Cagliari, 09042 Monserrato, Italy; mcollu@unica.it \\ 2 CNR Institute of Translational Pharmacology, 09010 Pula/Cagliari, Italy; \\ mariaantonietta.casu@ift.cnr.it (M.A.C.); ignazia.mocci@ift.cnr.it (I.M.) \\ 3 National School of Biological Sciences, IPN, Mexico City 07738, Mexico; maguilarsa@ipn.mx \\ * Correspondence: diana@unica.it (A.D.); mdsetzu@unica.it (M.D.S.); Tel.: +39-070-6754054/56 (A.D.); \\ +39-070-6754183 (M.D.S.)
}

Received: 7 December 2019; Accepted: 9 January 2020; Published: 14 January 2020

check for updates

\begin{abstract}
Within neurodegenerative syndromes, Parkinson's disease (PD) is typically associated with its locomotor defects, sleep disturbances and related dopaminergic (DA) neuron loss. The fruit fly, Drosophila melanogaster (D. melanogaster), with leucine-rich repeat kinase 2 mutants (LRRK2) loss-of-function in the WD40 domain, provides mechanistic insights into corresponding human behaviour, possibly disclosing some physiopathologic features of PD in both genetic and sporadic forms. Moreover, several data support the boosting impact of innate and adaptive immunity pathways for driving the progression of PD. In this context, human dialyzable leukocyte extracts (DLE) have been extensively used to transfer antigen-specific information that influences the activity of various immune components, including inflammatory cytokines. Hence, the main goal of our study was to ascertain the therapeutic potential of DLE from male and female donors on D. melanogaster LRRK2 loss-of-function, as compared to D. melanogaster wild-type (WT), in terms of rescuing physiological parameters, such as motor and climbing activities, which are severely compromised in the mutant flies. Finally, in search of the anatomical structures responsible for restored functions in parkinsonian-like mutant flies, we found a topographical correlation between improvement of locomotor performances and an increased number of dopaminergic neurons in selective areas of $L R R K 2$ mutant brains.
\end{abstract}

Keywords: Drosophila melanogaster; LRRK2 loss-of-function; Parkinson's disease; motor functions; human dialyzed leukocyte extract

\section{Introduction}

Parkinson's disease (PD) is a chronic, multifactorial and genetically heterogeneous neurodegenerative disorder with a tremendous epidemiology that accounts for 1-2\% of incidences in the population over the age of 60 years [1], with a peak of 3.5\% at ages 85-89 [2,3]. It is distinguished by integrated motor symptoms, namely, rigidity, bradykinesia, resting tremors and postural instability. Although it is perceived as a movement disorder, it is often accompanied by a plethora of nonmotor symptoms, including the decline of cognition, memory, visuospatial functions, anosmia, sleep disturbances and depression, ultimately leading to dementia. Its etiopathogenesis is still controversial, since most cases seem to be sporadic or related to environmental toxin exposure [4-8]. Only up to $10 \%$ of PD cases are clearly associated with monogenic mutations that involve 15 contributing genes responsible for familial forms and cause early, 
juvenile and late onset [9]. Among these [10], the leucine-rich repeat kinase 2 (LRRK2) gene contains multiindependent domains that are widely expressed within different brain areas, such as the cortex, striatum, hippocampus and cerebellum, and in dopaminergic neurons of the substantia nigra [11-14]. Notably, LRRK2-PD bears the pathological phenotype that mostly overlaps with the sporadic form of the disease. The discovery of mutations in the LRRK2-encoding gene has disclosed novel perspectives in PD genetics [15-18]. In fact, the LRRK2 G2019S mutation is more diffuse in Caucasian individuals, including up to $2 \%$ of sporadic cases of PD $[19,20]$. LRRK2 is a large protein implicated in both guanosine triphosphate (GTP)-ase and kinase activities that controls several signal transduction cascades necessary for mitochondrial metabolism; synaptic vesicle trafficking associated with endocytosis; retromer complex modulation; and, finally, autophagy [21,22].

With regard to the PD genetic approach, the Drosophila melanogaster (D. melanogaster) fly represents an extremely powerful model for studying neuronal dysregulation, providing a paramount tool for the dissection of molecular events in the neurodegenerative disease's aetiology and progression [23].

In addition, and with respect to the LRRK2 gene, D. melanogaster mutants that overlap significant features with the human condition have boosted several studies in PD research because of their alternative strategies for disease treatment [24-26] by means of both mutants' gain-of-function and loss-of-function kinase 2 domains [27-29]. In particular, the missense G2385R substitution within the WD40 domain severely affects autophosphorylation activity [30], leads to a partial loss-of-function of $L R R K 2$, and is pathologically relevant for PD, being associated with an increased risk of developing idiopathic PD among Chinese and Korean ethnicities [31,32]. Interestingly, the kinase activity down-regulated in such mutants can be restored by over-expressing the gain-of-function mutation of the gene [33].

Moreover, previous reports [34,35] have sustained the validity of the LRRK2 WD40 loss-of-function $\left(L R R K 2^{\mathrm{WD}} 40\right)$ as an animal model of parkinsonism in D. melanogaster.

Several reports have pointed out how innate and adaptive immunity pathways can sustain the progression of PD. However, the real impact of activated glial cells and inflammatory molecules in terms of neurodegeneration or neuroprotection is still under debate [36]. Moreover, the infiltration of circulating $\mathrm{T}$ lymphocytes into the brain can produce dramatic effects, since in vivo blood-brain barrier (BBB) dysfunction has been documented as a triggering event in parkinsonian patients [37]. This experimental evidence that highlights the importance of an intact BBB has been confirmed in the last decade by several papers, as recently reviewed by Sweeney MD et al. [38].

Therefore, in order to elucidate the potential impact of anti-inflammatory molecular signals released by $\mathrm{T}$ cells, we have tested dialyzable leukocyte extracts (DLE) as a means of alternative direct delivery to transfer antigen-specific information for cell-mediated immunity (CMI). This is the rationale underlying the phrase "transfer factor" (TF) to describe this pool of molecules. Since the pioneering work of Lawrence [39], TF has been prepared by disrupting lymphocytic plasmalemma and subjecting the recovered lysates to dialysis for collecting the biological fractions with molecular weights (MWs) less than $12 \mathrm{kDa}$. For many years, DLE have been used successfully as an adjuvant or primary therapy, not only for viral, parasitic, fungal and bacterial infections but also for immunodeficiencies, neoplasia, allergies and autoimmune diseases, despite the fact there is no clear understanding of the molecular mechanisms driving the beneficial effects in experimental and clinical studies [40]. Moreover, there is no report yet dealing with possible modulatory effects in the central nervous system being affected by neurodegenerative syndromes with an important inflammatory component, such as PD. Thus, the aim of this paper was to investigate the therapeutic potential of DLE on D. melanogaster LRRK2 loss-of-function variants, compared to D. melanogaster wild-types (WTs, Canton-S), in terms of physiological parameters that are severely compromised in the mutant flies, such as walking and climbing activities. Given that preliminary results were in favour of significant alterations in monitored pathognomonic symptoms, we found that it could be reasonable to verify the possible higher or lower presence of dopaminergic neuronal clusters in both the anterior and posterior parts of the Drosophila brain. Finally, we concluded that, at least with regard to specific lysate treatments, there was a direct 
relationship between the amelioration of some motor performances and the increased number of dopaminergic neurons in selective areas of LRRK2 mutant brains.

\section{Materials and Methods}

Adult wild-types (WTs, Canton-S) and LRRK ${ }^{\mathrm{WD} 40}$ mutants (LRRK ${ }^{\mathrm{ex} 1}$ \#34750, simply termed LRRK from Bloomington Stock Center) Drosophila melanogaster (D. melanogaster) males were used. Soon after emergence from pupae, WT and LRRK mutant males were separated from females. WT and mutant flies were reared on a standard cornmeal-yeast-agar medium in controlled environmental conditions $\left(24-25^{\circ} \mathrm{C}, 60 \%\right.$ relative humidity, light/dark $\left.=12 / 12 \mathrm{~h}\right)$. Flies ranging $10-15$ days in age were tested in accordance with previous experiments [34]. In addition, groups of mutant and WT flies were reared on a standard medium supplemented with DLE from both female and male patients at two different concentrations $(0.01 \%$ and $0.1 \%)$. All experiments were performed using adult flies aged 8-9 days (group I) and 15-16 days (group II), for a total of 20-40 subjects.

\subsection{Motor Activity}

The effects of human male and female DLE were assayed at 7 and 14 days of treatment at the above age steps in male $L R R K$ and WTs. One day before ending the treatment, all flies from each experimental group, i.e., untreated WTs and LRRK and DLE-treated WTs and $L R R K$, were individually transferred to a vertically-positioned plastic tube (length $6.5 \mathrm{~cm}$, diameter $0.4 \mathrm{~cm}$ ) plugged at the bottom and with the opposite side filled with the standard cornmeal-yeast-agar medium, with or without DLE. Twenty-four hours of sleep and motor activity were recorded using the Drosophila Activity Monitor System (DAMS; Trikinetics, Waltham, MA, USA), and activity was determined as each fly moved back and forth in the tube and interrupted the infrared light beam that bisected each tube. Therefore, every time the fly crossed the tube was counted as movement, measured over a $1 \mathrm{~min}$ period. DAMS monitors were housed inside environmental chambers where temperature and humidity were kept constant.

\subsection{Climbing Assay}

The climbing assay (negative geotaxis assay) was used to assess locomotor ability [34]. Climbing data were obtained from different age groups: (I) 7-8 days old and (II) 14-15 days old, of WTs and LRRK D. melanogaster in basal and treated conditions. Cohorts of 30 flies from each experimental group were subjected to the assay. Flies were placed individually in a vertically positioned plastic tube (length $10 \mathrm{~cm}$, diameter $1.5 \mathrm{~cm}$ ) with the bottom plugged. Climbing time (expressed in seconds) was recorded upon crossing a line drawn $6 \mathrm{~cm}$ from the bottom. The number of insects that climbed to or above this line within $10 \mathrm{~s}$ was recorded and expressed as a percentage of total flies.

\subsection{DLE Preparation}

TF was prepared by means of buffy coats of healthy blood donors obtained from the Immunohematology Unit of Brotzu Hospital (Cagliari, Italy) upon permission of its ethics committee (registry no. 6397/2015). After several cycles of centrifugations and washes, the leukocyte pellet was resuspended in $\mathrm{NaCl}(0.9 \%)$ and immersed in nitrogen liquid. Samples were subjected to repeated cycles of freezing and thawing in order to favour the complete cellular lysis, including the plasma membranes, thereby making it possible to collect the whole extracted fraction. This content was transferred into $15 \mathrm{~mL}$ dialysis tubes (Slide-A-Lyzer MINI dialysis devise, 10K MW; Thermo Scientific, Bedford, MA, US) according to the manufacturer's procedure for the recovery of proteins and macromolecules above $10 \mathrm{kDa}$ and left overnight in constant agitation at room temperature. Finally, DLE obtained from both male and female patients were stored at $-70{ }^{\circ} \mathrm{C}$ until experimental use. 


\subsection{Immunohistochemistry}

Free-floating fluorescent immunostaining for tyrosine hydroxylase (TH) was performed on whole dissected adult brains. LRRK2 and WT Canton Drosophila were anesthetised on ice before brains were rapidly dissected and fixed with paraformaldehyde (4\%) in phosphate-buffered saline (PBS). After fixation and a rinse in PBS, brains were incubated with the TH primary antibody $(1: 100$, AB152, Millipore) and normal donkey serum (10\%) in PBS with Tween-20 (PBST, $0.3 \%$ ) at $4{ }^{\circ} \mathrm{C}$ for $72 \mathrm{~h}$. After rinsing, the brains were incubated with a donkey anti-rabbit Alexa Fluor 594 secondary antibody (1:200, Jackson ImmunoResearch) and normal donkey serum (10\%) in PBST at $4{ }^{\circ} \mathrm{C}$ for $72 \mathrm{~h}$. Afterwards, the brains were mounted on glass slides and coverslipped with Vectashield antifading medium. Fluorescent images were captured by a fluorescence spinning-disk confocal microscope (Crisel Instruments, Roma, Italy). Each sample was scanned through Z-stacks ( $63 \times$ objective). The number of TH-positive neurons of different clusters in each hemisphere of each stack was counted manually with the use of NIH Image software (version 1.51i, NIH, Bethesda, MD, USA), and 10-20 hemispheres were analysed for each group of flies.

\subsection{Statistics}

All significant differences were evaluated with a two-way ANOVA and/or one-way ANOVA, followed by a post-hoc analysis when appropriate (Tukey's test).

\section{Results}

\subsection{Motor Activity}

As expected, a significant difference in locomotor activities between WT and LRRK strains was found without any variations after male DLE (mDLE) $\left[\mathrm{F}_{(1,248)}=4.311, p=0.0389\right]$ and female DLE (fDLE) $\left[\mathrm{F}_{(1,175)}=6.476, p=0.0118\right]$, after seven days of treatment with both doses. Neither treatment doses nor their interactions with the strains were significant $(p>0.05)$. However, data suggest a mild improvement in mutants at the highest concentration of fDLE $(0.1 \%)$ and, surprisingly, at the lowest concentration $(0.01 \%)$ of mDLE (Figures $1 \mathrm{~A}$ and 2, respectively).

On the contrary, the analysis of motor activity showed a more significant difference with mDLE upon 14 days of treatment, in terms of activity performance amelioration, compared to the fDLE-treated group. Motor activity was enhanced in the flies $L R R K$ group with $0.1 \%$ mDLE $(p<0.01)$. The analyses of treated and control fly groups revealed that only the most concentrated dose of mDLE was able to trigger improvements in motor activity. A two-way ANOVA found a statistically significant strain $\left[\mathrm{F}_{(1,238)}=19.42, p<0.0001\right]$ and treatment $\left[\mathrm{F}_{(2,38)}=5.619, p=0.0041\right]$ effect but not a strain $\times$ treatment interaction $\left[\mathrm{F}_{(2,238)}=0.5201, p=0.5952\right]$ effect indicative of overall activity (Figure 1b). A lower-order one-way ANOVA showed a significant effect of $0.1 \% \mathrm{mDLE}$ in the $L R R K$ mutants $(p<0.01)$, compared to $L R R K$ control flies. The most apparent difference was detected in the LRRK group at two weeks with both doses $\left[\mathrm{F}_{(1,143)}=35.63, p<0.0001\right]$ (Figure $1 \mathrm{~b}$ ). Conversely, the WT flies treated with both mDLE and fDLE $(0.01 \%$ and $0.1 \%)$ did not show any significant drug effects on motor activity compared to untreated controls (Figure 1A,B, Figures 2 and 3, respectively). For the group treated with fDLE, the two-way ANOVA found a statistically significant effect only for the strain $\left[\mathrm{F}_{(1,143)}=35.63, p<0.0001\right)$ but not for treatment $\left[\mathrm{F}_{(2,143)}=0.9761, p=0.3793\right]$ or treatment $\times$ strain $\left[\mathrm{F}_{(2,143)}=0.2869, p=0.7510\right]$. The time-course activity measured for $24 \mathrm{~h}$ at 7 and 14 days is illustrated in Figure 2A,C for mDLE and Figure $3 a, c$ for fDLE at 7 days, respectively. Interestingly, there was a common feature during the whole observed period represented by a peak in motor activity from the 10 to 15-hours interval in both strains, with specific significant values always expressed at $13 \mathrm{hr}$ (Figure 1B,b and Figure 3b,d, respectively at 14 days). In the Supplementary Material, Data in Figure S1 are represented as box whisker graphs for more transparency in showing their variability. 


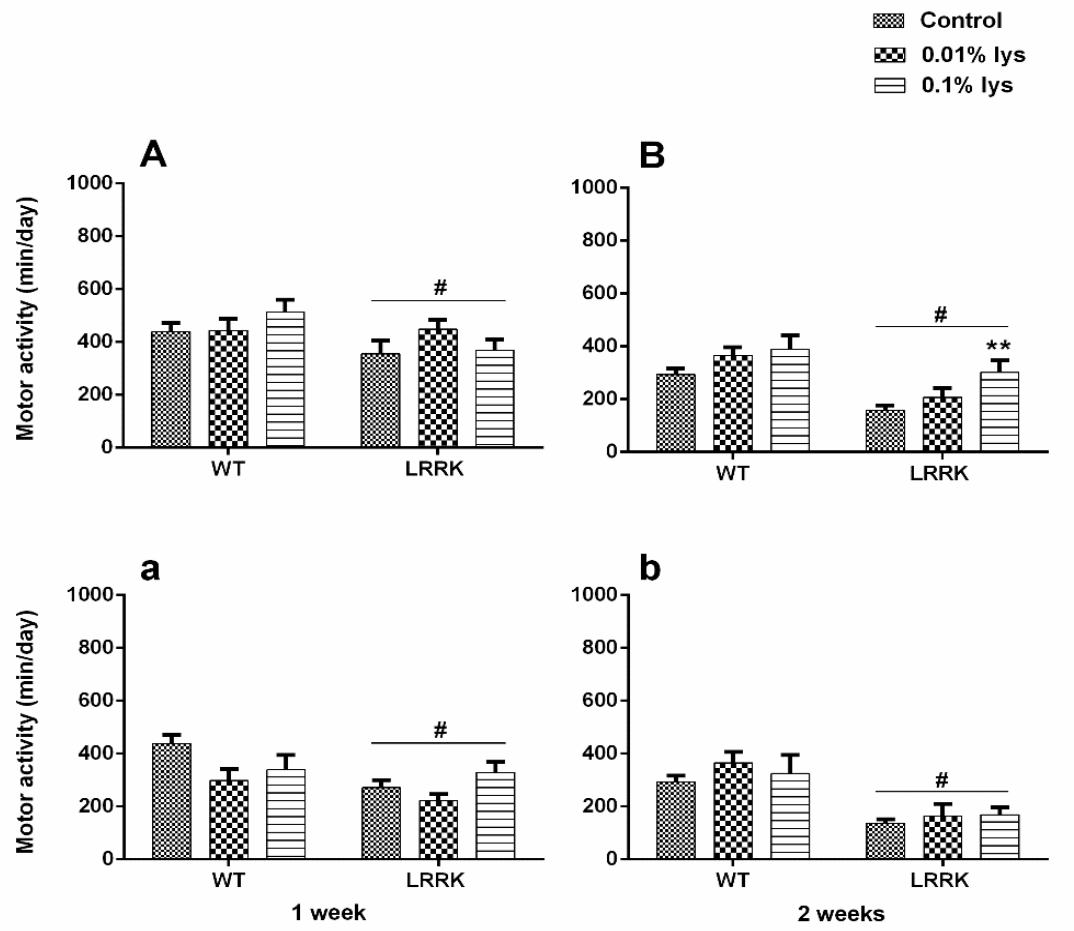

Figure 1. Effects of male dialyzable leukocyte extracts (mDLE) and female dialyzable leukocyte extracts (fDLE) treatments on motor activity of wild-type (WT) and LRRK mutant flies. Total motor activity $(24 \mathrm{~h})$ of WT and LRRK mutant flies treated with $\operatorname{mDLE}(\mathbf{A}, \mathbf{B})$ or fDLE $(\mathbf{a}, \mathbf{b})$ in their diet at 7 days and 14 days is shown. Bars represent mean \pm standard error of mean (SEM) of 20-40 fly groups in triplicate. $\#=p<0.01 L R R K$ strain versus WT group and ${ }^{* *}=p<0.001$ LRRK C versus LRRK fDLE $(0.1 \%)$.

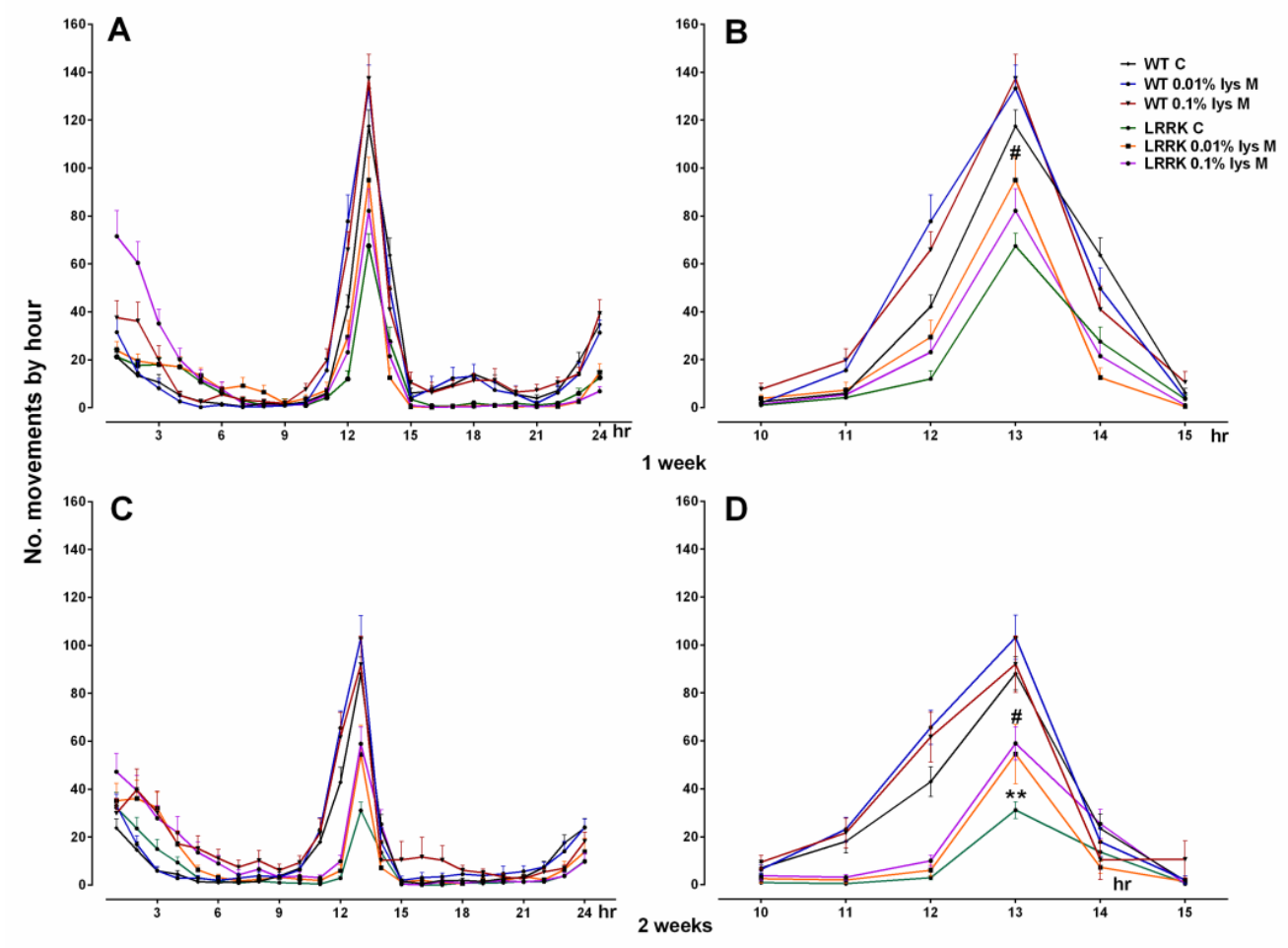

Figure 2. This illustrates the $5 \mathrm{hr}$ and $24 \mathrm{hr}$ time-course in WT and $L R R K$ mutant flies treated with mDLE. \# $=p<0.001 L R R K$ strain versus WTs and ${ }^{* *}=p<0.001$ LRKK C versus LRRK fDLE-treated $(0.01 \%$, Tukey's test). 


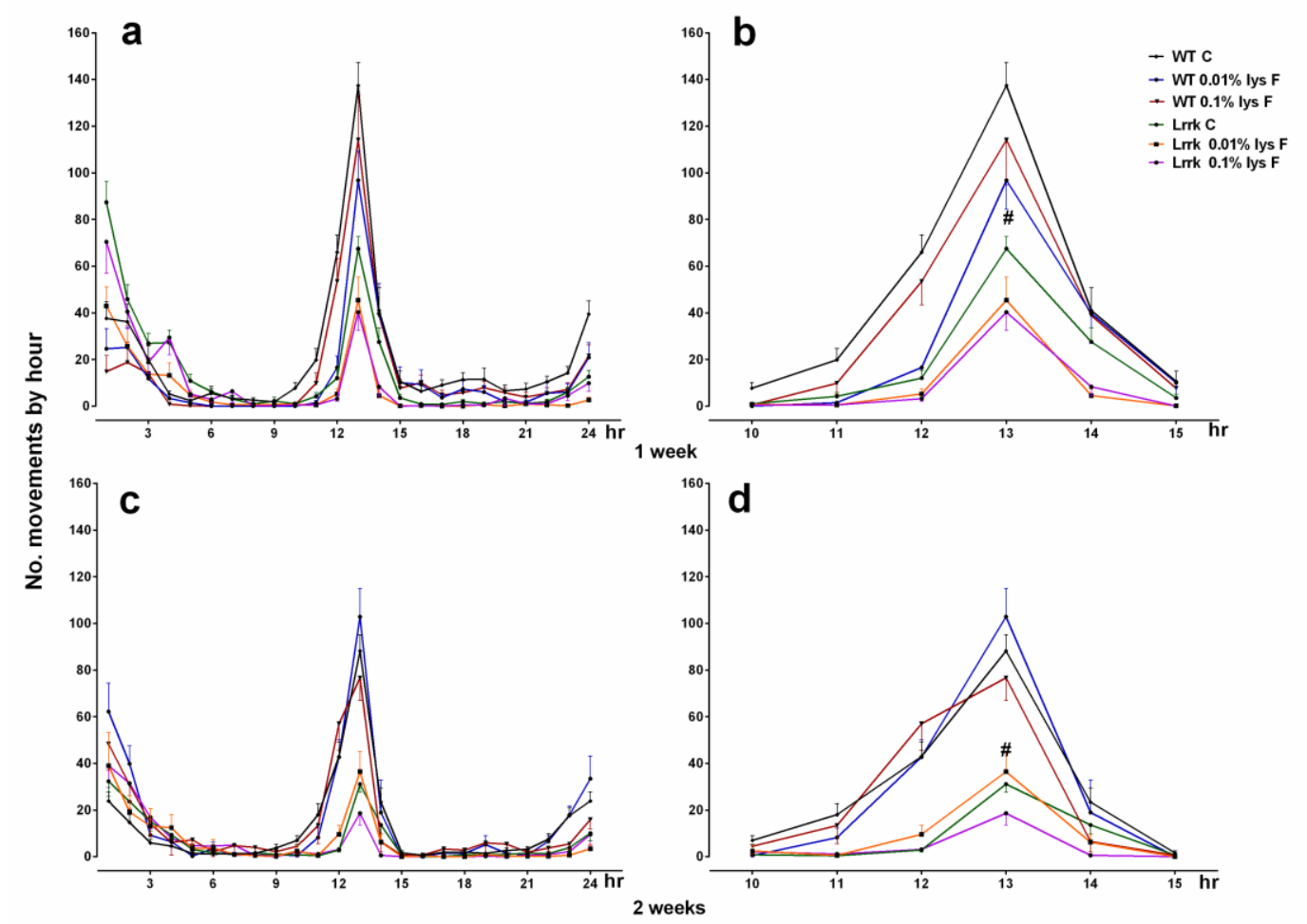

Figure 3. This illustrates the $5 \mathrm{hr}$ and $24 \mathrm{hr}$ time-course in WT and LRRK mutant flies treated with fDLE after 7 and 14 days of treatment. \# $=p<0.001$ LRRK strain versus WTs and ${ }^{* *}=p<0.001$ LRKK C versus $L R R K$ fDLE-treated (0.01\%, Tukey's test).

\subsection{Climbing Activity}

At only seven days, a statistically significant strain difference in climbing was observed independently in $\operatorname{mDLE}\left[\mathrm{F}_{(1,479)}=13.05, p=0.0003\right]$ and $\operatorname{fDLE}\left[\mathrm{F}_{(1,476)}=7.178, p=0.0076\right]$ treatments (Figure $\left.4 \mathrm{~A}, \mathrm{a}\right)$. Moreover, after 14 days, a significant increase in restored climbing performance was detected in control (nontreated) mutant $L R R K$ group, suggesting a motor disability recovery (Figure $4 \mathrm{~B}, \mathrm{~b}$ ). In particular, at two weeks, a statistically significant strain $\times$ treatment interaction $\left[\mathrm{F}_{(2,476)}=1.944, p=0.1443\right]$ and treatment-dependent effect $\left[\mathrm{F}_{(2,794)}=3.354, p=0.0354\right]$ (two-way ANOVA) was observed without any significant strain $\left[\mathrm{F}_{(1,794)}=1.815, p=0.1782\right]$ effect. However, a lower-order one-way ANOVA showed a significant effect of mDLE at both $0.01 \%$ and $0.1 \%$ concentrations for the LRRK mutants $(p<0.05)$, compared to WT control flies, where there was no treatment effect (Figure 4). Similarly, fDLE induced better performances when administered at 14 days, with a significant strain $\times$ treatment interaction $\left[\mathrm{F}_{(2,449)}=9.096, p=0.0001\right]$ but no strain $\left[\mathrm{F}_{(1,449)}=0.01557, p=0.9008\right]$ or treatment effect $\left[\mathrm{F}_{(2,449)}=2.141\right.$, $p=0.1187$ ] due to the significant differences in variance within the groups (Bartlett's test, $p=0.0001$; Figure $4 \mathrm{~b}$ ). Hence, after a lower-order one-way ANOVA, the differences between strain and treatment were evident and significant $\left[\mathrm{F}_{(4,601)}=8.469, p<0.0001\right]$ (Figure $4 \mathrm{~b}$ ). In the Supplementary Material, Figure S2 illustrates the same data as whiskers graphs for more transparency in showing their variability. 
A

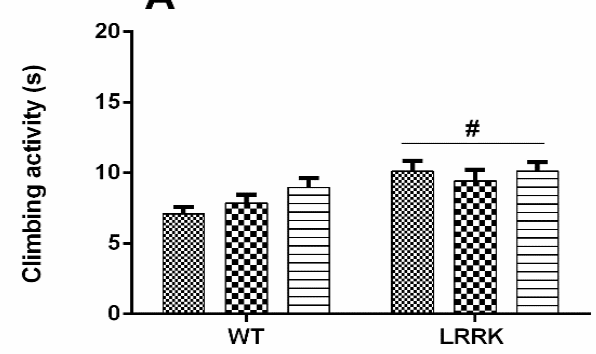

a

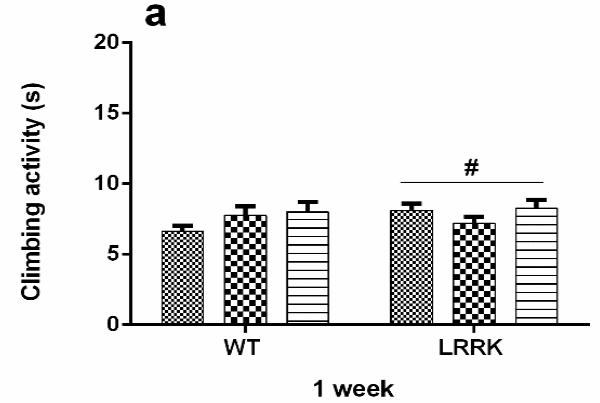

B

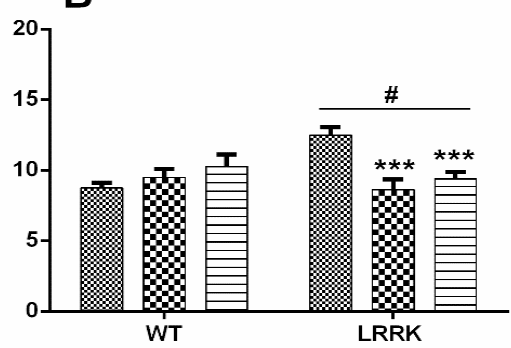

b

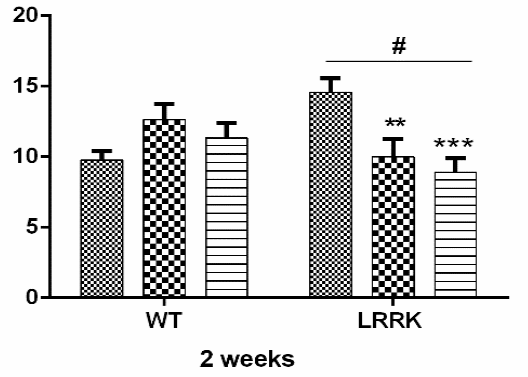

Figure 4. Effects of mDLE and fDLE treatments on climbing activity of mutant WT and LRRK flies, with $\operatorname{mDLE}(\mathbf{A}, \mathbf{B})$ and fDLE $(\mathbf{a}, \mathbf{b})$ in their diet at $7(\mathbf{A}, \mathbf{a})$ and $14(\mathbf{B}, \mathbf{b})$ days of treatment, respectively. Bars represent mean \pm SEM of 20-40 fly groups in triplicate. \# $=p<0.05$ WTs versus LRRK in (A), $(\mathbf{a}, \mathbf{b})$ groups; $^{* *}=p<0.01$ LRRK versus WTs control and WT mDLE $(0.01 \%)$ and ${ }^{* * *}=p<0.0001$ LRRK versus $L R R K(0.01 \%)$ and $\operatorname{mDLE}(0.1 \%)$, respectively. ${ }^{* *}=p<0.01 L R R K$ versus $L R R K(0.01 \%)$ and *** $=p<0.0001 L R R K$ versus $L R R K \operatorname{fDLE}(0.1 \%$, Tukey's test).

\subsection{Immunohistochemistry}

As shown in Figure 5, we focused on the anterior dopaminergic (DA) clusters, protocerebral anterior medial (PAM) and protocerebral anterior lateral (PAL), on the posterior clusters, protocerebral posterior laterals (PPL1 and PPL2) and protocerebral posterior medial: superior-medial/inferior-medial (PPM1/2 and PPM3) in order to ascertain any possible number variations triggered by mDLE and fDLE after 14 days, since the physiological parameters described above were significantly recovered by this timepoint. The $L R R K$ flies showed a reduction of DA neurons with respect to WT groups in all posterior clusters. In particular, for the PPL1, there was a significant strain $\left[\mathrm{F}_{(2,64)}=15.83, p<0.0001\right]$, treatment $\left[\mathrm{F}_{(1,64)}=45.03, p<0.0001\right]$ effect and strain $\times$ treatment interaction $\left[\mathrm{F}_{(2,64)}=5.893, p=0.0045\right]$, while in the PPM1/2, only significant strain $\left[\mathrm{F}_{(1,58)}=24.91, p<0.0001\right]$ and treatment $\left[\mathrm{F}_{(2,58)}=5.942, p=0.0045\right]$ effects were found but not a strain $\times$ treatment interaction $\left[\mathrm{F}_{(2,58)}=31.40, p=0.0507\right]$. The treatment with mDLE and fDLE after 14 days significantly prevented the loss of DA neurons in the posterior clusters PPL1, PPM3 and PPM1/2 of LRRK. The only cluster not responsive to the DLE effects was the PPL2 (strain: $\left[\mathrm{F}_{(1,49)}=0.005574, p=0.9408\right]$; treatment: $\left[\mathrm{F}_{(2,49)}=1.437, p=0.2475\right]$ and strain $\times$ treatment: $\left.\left[\mathrm{F}_{(2,49)}=1.316, p=0.2774\right]\right)$. In particular, fDLE seemed to always be more successful for neuronal rescue compared to the mDLE, and in the case of the PPM1/2 cluster, only fDLE displayed an upregulation of DA neurons. Moreover, the PPL1 showed significant strain $\left[\mathrm{F}_{(2,64)}=15.83, p<0.0001\right]$; treatment $\left[\mathrm{F}_{(1,64)}=45.03, p<0.0001\right]$ effect and strain $\times$ treatment interaction $\left[\mathrm{F}_{(2,64)}=5.893, p=0.0045\right]$, while in the PPM1/2, only significant strain $\left[\mathrm{F}_{(1,58)}=24.91, p<0.0001\right]$ and treatment $\left[\mathrm{F}_{(2,58)}=5.942\right.$, $p=0.0045]$ effect but not strain $\times$ treatment interaction $\left[\mathrm{F}_{(2,58)}=3140, p=0.0507\right]$. PPM3 showed strain $\left[\mathrm{F}_{(1,47)}=32.92, p<0.0001\right]$, treatment $\left[\mathrm{F}_{(2,47)}=12.93, p<0.0001\right]$ effect and strain $\times$ treatment interaction 
$\left[\mathrm{F}_{(2,47)}=10.67, p=0.0002\right]$ (Figure 6). No differences were found in the anterior clusters PAM and PAL. In the Supplementary Material, Figure S3 represents the anterior and posterior DA clusters in WT flies (A). Representative image stacks (63×) show the distribution of dopaminergic neurons in the different clusters in WT control flies. The bars represent 100 (Panel A) and $10 \mu \mathrm{m}$ (Panel B).
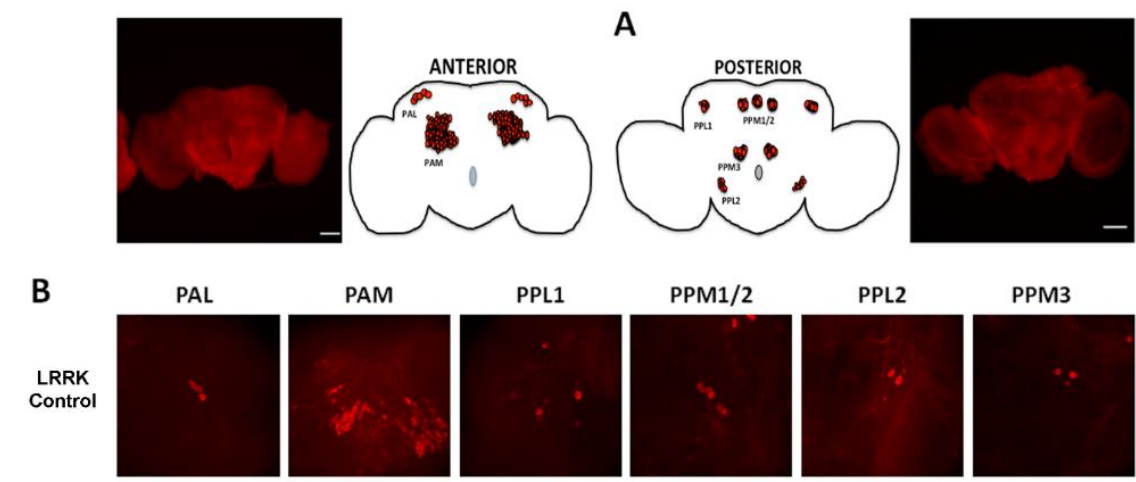

PPL2

PPM3
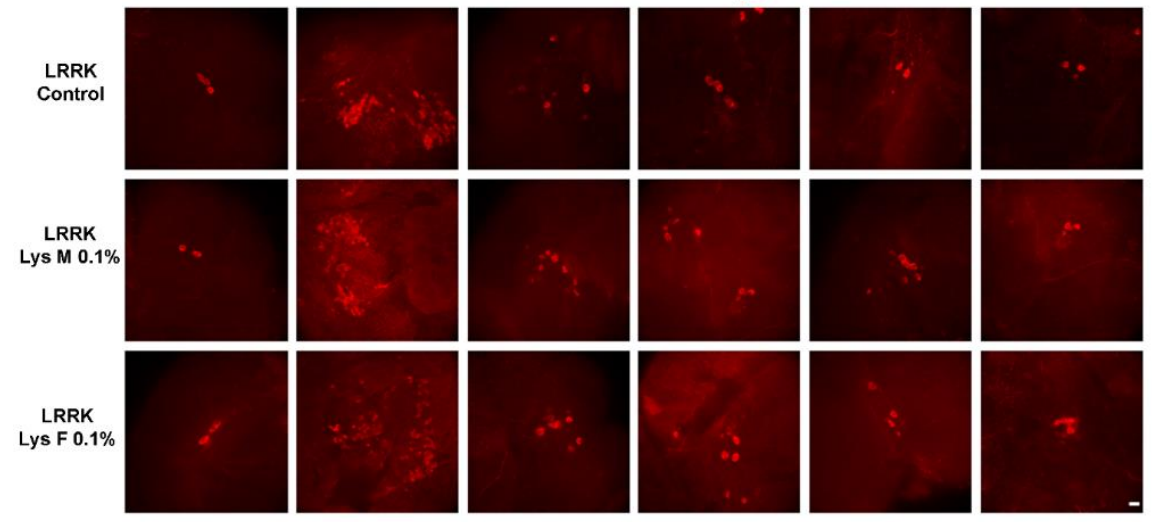

Figure 5. Anterior and posterior dopaminergic (DA) clusters in $L R R K$ flies. $A=$ micrograph (10 $\times$ ) and schematic representation of brain anterior and posterior faces where the DA clusters reside. $\mathrm{B}=$ representative image stacks $(63 \times)$ showing the distribution of dopaminergic neurons in the different clusters in LRRK control and mDLE (LysM) and fDLE (LysF)-treated groups. The bars represent 100 (Panel A) and $10 \mu \mathrm{m}$ (Panel B).

\section{4 days treatment}
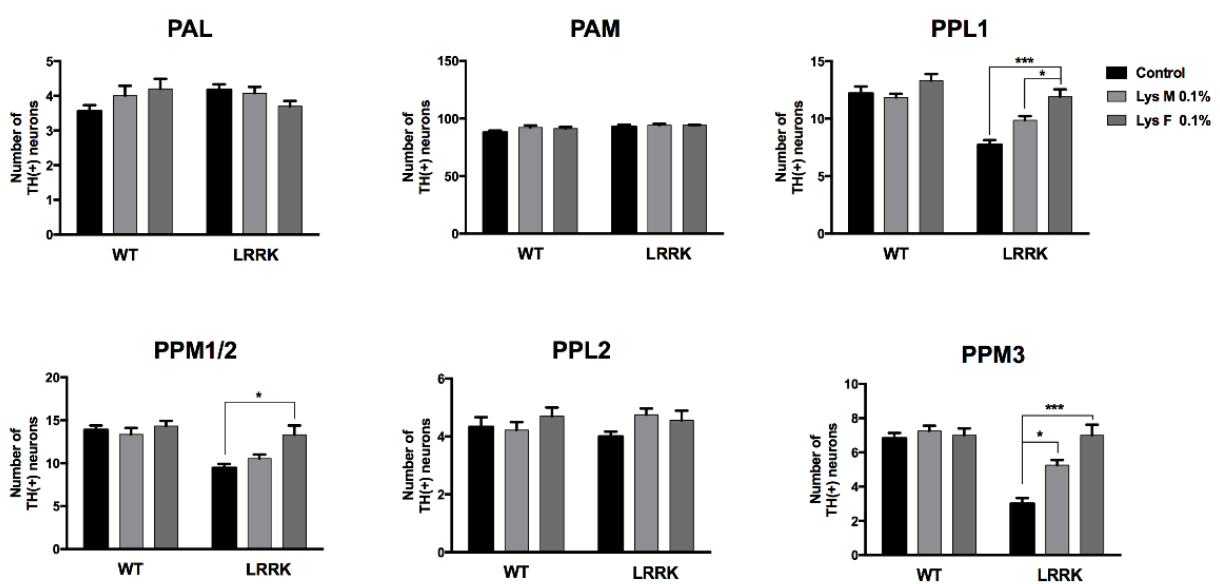

Figure 6. Effects of mDLE and fDLE treatments on neuron numbers in DA clusters of WT and LRRK flies. Graphs show no differences in the number of DA neurons in protocerebral anterior medial (PAM) and protocerebral anterior lateral (PAL) of the different groups. The treatments with mDLE and fDLE at 14 days significantly prevent the loss of DA neurons in the posterior clusters (protocerebral posterior lateral (PPL)1, PPL2, and protocerebral posterior medial (PPM)1/2 and PPM3) of LRRK2 WD40. ${ }^{*}=p<0.05 ;{ }^{* *}=p<0.001$ in control groups (10 hemispheres for each group, Tukey's test). 


\section{Discussion}

It is well-established that mutations in the LRRK2 gene are the most frequent cause of familial PD [41,42]. Clinically, mutant $L R R K 2-P D$ patients are often considered indistinguishable from sporadic patients. Likewise, LRRK2 is also highly recruited in immune cells and its variability is under the control of immune stimulation, providing compelling evidence that both systemic and central nervous system (CNS) inflammations interact in PD pathophysiology [43]. As a matter of fact, the human DLE used in this study as a potential "transfer factor" of cellular-mediated immunity opens up intriguing scenarios for controlling and interpreting the progression of PD. Moreover, despite unknown molecular mechanisms, specific signalling pathways for cellular survival and activation involve the $D$. melanogaster Toll protein, which is homologous to the receptors for human IL-1 (proinflammatory cytokine) [44]. Hence, it is feasible that selected and specific DLE molecules that are prone to binding Toll-like receptors have recently been regarded as alternative therapy in PD [45]. In principle, the overall analyses of activities have shown that mutant $L R R K$ flies require a longer period (two weeks) of DLE treatment in order to trigger motor and climbing performances similar to WT flies. This result was observed in climbing activity irrespective of the DLE origin (male or female). Only for motor activity was the mDLE more effective at the highest dose, compared to the fDLE. Hence, in our search for anatomical changes indicative of motor function improvements, we measured with immunohistochemistry the number of $\mathrm{TH}$-positive neurons in the anterior and posterior clusters highly related to motor ability. In particular, the dopaminergic PPM3 cluster projects its fibres into the central complex, which is involved in controlling locomotion and arousal [46]. The immunohistochemical results were in agreement with the above hypothesis, but only posterior clusters, including PPL1 and PPM1/2, were involved with the upregulation of DA neurons. Most notably, the fDLE $(0.1 \%)$ were always more effective in promoting the increase of DA neurons, compared to the mDLE. In conclusion, this is the first paper that has investigated the positive effects of DLE in sustaining motor parameters severely affected in mutant LRKK by rescuing those DA clusters that are highly related to motor ability. Finally, we can also speculate whether more clear-cut results could be generated in a different dose-dependent experimental setting as a direct reflection of inflammatory imbalances in pro- and antiinflammatory molecules [47]. For that purpose, experiments are in progress to analyse the biochemical composition of DLE from male and female subjects in order to ascertain possible molecular alternatives to be recruited, not only for immunomodulation but also for neuroprotective interventions.

Supplementary Materials: The following are available online at http://www.mdpi.com/2076-3425/10/1/45/s1: Figure S1, Motor activity of WT and LRRK mutant flies treated with mDLE (A-B) and fDLE (a-b) in their diet at 7 days (A-a) and 14 days (B-b) during 24-h daytime. The top and bottom of the box and whisker plots show the upper and lower quartiles, respectively. The horizontal line in the middle indicates the median of the corresponding distribution, while the minimum and maximum observed values are indicated by the bars connected to the box. \#, P $<0.001$ versus the WT strain; Figure S2, Climbing activity of WT and LRRK mutant flies treated with mDLE (A-B) and fDLE (a-b) in their diet at 7 days (A-a) and 14 days (B-b) during 24-h daytime. The top and bottom of the box and whisker plots show the upper and lower quartiles, respectively. The horizontal line in the middle indicates the median of the corresponding distribution, while the minimum and maximum observed values are indicated by the bars connected to the box. $\#, P<0.001$ versus the WT strain; $* * *, P<0.0001$ LRRKC vs LRRK $0.01 \%$ and $0,1 \% \mathrm{mDLE}$, and $0.1 \%$ fDLE, respectively. ${ }^{* *}, P<0.001$ LRRKC vs LRRK $0.01 \%$ fDLE; Figure S3, Anterior and posterior DA clusters in WT flies. Distribution of Anterior and posterior DA clusters (A); Representative image stacks (63X) showing the distribution of dopaminergic neurons in the different clusters in WT control flies. The bars represent 100 (Panel A) and $10 \mu \mathrm{m}$ (Panel B).

Author Contributions: Conceptualization: A.D., M.C., M.A.-S. and M.D.S.; methodology: M.C., M.A.-S. and M.D.S.; software: M.C., M.A.C., I.M. and M.D.S.; investigation: A.D., M.A.C., I.M. and M.D.S.; resources: A.D., M.C. and M.D.S.; data curation: M.C. and M.D.S.; writing-review and editing: A.D. and M.C.; supervision: A.D. and M.D.S. and funding acquisition: A.D., M.C. and M.D.S. All authors have read and agreed to the published version of the manuscript.

Funding: This research and APC were funded by the University of Cagliari, Italy.

Acknowledgments: Authors acknowledge technical support from CeSAR, University of Cagliari.

Conflicts of Interest: The authors declare no conflict of interest. 


\section{References}

1. $\quad$ De Rijk, M.C.; Tzourio, C.; Breteler, M.M.; Dartigues, J.F.; Amaducci, L.; Lopez-Pousa, S.; Manubens-Bertran, J.M.; Alpérovitch, A.; Rocca, W.A. Prevalence of parkinsonism and Parkinson's disease in Europe: The EUROPARKINSON Collaborative Study. European Community Concerted Action on the Epidemiology of Parkinson's disease. J. Neurol. Neurosurg. Psychiatry 1997, 62, 10-15. [CrossRef] [PubMed]

2. Twelves, D.; Perkins, K.S.; Counsell, C. Systematic review of incidence studies of Parkinson's disease. Mov. Disord. 2003, 18, 19-31. [CrossRef] [PubMed]

3. De Lau, L.M.L.; Breteler, M.M.B. Epidemiology of Parkinson's disease. Lancet Neurol. 2006, 5, 525-535. [CrossRef]

4. Tanner, C.M.; Kamel, F.; Ross, G.W.; Hoppin, J.A.; Goldman, S.M.; Korell, M.; Marras, C.; Bhudhikanok, G.S.; Kasten, M.; Chade, A.R.; et al. Rotenone, paraquat, and Parkinson's disease. Environ. Health Perspect. 2011, 119, 866-872. [CrossRef]

5. Racette, B.A.; Willis, A.W. Time to change the blind men and the elephant approach to Parkinson disease? Neurology 2015, 85, 190-196. [CrossRef]

6. Covy, J.P.; Giasson, B.I. $\alpha$-Synuclein, leucine-rich repeat kinase-2, and manganese in the pathogenesis of Parkinson disease. Neurotoxicology 2011, 32, 622-629. [CrossRef]

7. Wright Willis, A.; Evanoff, B.A.; Lian, M.; Criswell, S.R.; Racette, B.A. Geographic and ethnic variation in Parkinson disease: A population-based study of US Medicare beneficiaries. Neuroepidemiology 2010, 34, 143-151. [CrossRef]

8. Willis, A.W.; Evanoff, B.A.; Lian, M.; Galarza, A.; Wegrzyn, A.; Schootman, M.; Racette, B.A. Metal emissions and urban incident Parkinson disease: A community health study of Medicare beneficiaries by using geographic information systems. Am. J. Epidemiol. 2010, 172, 1357-1363. [CrossRef]

9. Plotegher, N.; Duchen, M.R. Crosstalk between Lysosomes and Mitochondria in Parkinson's Disease. Front. Cell Dev. Biol. 2017, 5, 110. [CrossRef]

10. Verstraeten, A.; Theuns, J.; Van Broeckhoven, C. Progress in unraveling the genetic etiology of Parkinson disease in a genomic era. Trends Genet. 2015, 31, 140-149. [CrossRef]

11. Biskup, S.; Moore, D.J. Detrimental deletions: Mitochondria, aging and Parkinson's disease. Bioessays 2006, 28, 963-967. [CrossRef] [PubMed]

12. Higashi, S.; Biskup, S.; West, A.B.; Trinkaus, D.; Dawson, V.L.; Faull, R.L.; Waldvogel, H.J.; Arai, H.; Dawson, T.M.; Moore, D.J.; et al. Localization of Parkinson's disease-associated LRRK2 in normal and pathological human brain. Brain Res. 2007, 1155, 208-219. [CrossRef] [PubMed]

13. Galter, D.; Westerlund, M.; Carmine, A.; Lindqvist, E.; Sydow, O.; Olson, L. LRRK2 expression linked to dopamine-innervated areas. Ann. Neurol. 2006, 59, 714-719. [CrossRef] [PubMed]

14. Taymans, J.M.; Van den Haute, C.; Baekelandt, V. Distribution of PINK1 and LRRK2 in rat and mouse brain. J. Neurochem. 2006, 98, 951-961. [CrossRef] [PubMed]

15. Zimprich, A.; Biskup, S.; Leitner, P.; Lichtner, P.; Farrer, M.; Lincoln, S.; Kachergus, J.; Hulihan, M.; Uitti, R.J.; Calne, D.B.; et al. Mutations in LRRK2 cause autosomal-dominant parkinsonism with pleomorphic pathology. Neuron 2004, 44, 601-607. [CrossRef] [PubMed]

16. Bonifati, V. Parkinson's disease: The LRRK2-G2019S mutation: Opening a novel era in Parkinson's disease genetics. Eur. J. Hum. Genet. 2006, 14, 1061-1062. [CrossRef]

17. Xie, C.L.; Pan, J.L.; Wang, W.W.; Zhang, Y.; Zhang, S.F.; Gan, J.; Liu, Z.G. The association between the LRRK2 G2385R variant and the risk of Parkinson's disease: A meta-analysis based on 23 case-control studies. Neurol. Sci. 2014, 35, 1495-1504. [CrossRef]

18. Mata, I.F.; Kachergus, J.M.; Taylor, J.P.; Lincoln, S.; Aasly, J.; Lynch, T.; Hulihan, M.M.; Cobb, S.A.; Wu, R.M.; Lu, C.S.; et al. Lrrk2 pathogenic substitutions in Parkinson's disease. Neurogenetics 2005, 6, 171-177. [CrossRef]

19. Berg, D.; Schweitzer, K.J.; Leitner, P.; Zimprich, A.; Lichtner, P.; Belcredi, P.; Brüssel, T.; Schulte, C.; Maass, S.; Nägele, T.; et al. Type and frequency of mutations in the LRRK2 gene in familial and sporadic Parkinson's disease *. Brain 2005, 128, 3000-3011. [CrossRef]

20. Schrag, A.; Schott, J.M. Epidemiological, clinical, and genetic characteristics of early-onset parkinsonism. Lancet Neurol. 2006, 5, 355-363. [CrossRef]

21. Wallings, R.; Manzoni, C.; Bandopadhyay, R. Cellular processes associated with LRRK2 function and dysfunction. FEBS J. 2015, 282, 2806-2826. [CrossRef] [PubMed] 
22. Price, A.; Manzoni, C.; Cookson, M.R.; Lewis, P.A. The LRRK2 signalling system. Cell Tissue Res. 2018, 373, 39-50. [CrossRef] [PubMed]

23. Aryal, B.; Lee, Y. Disease model organism for Parkinson disease: Drosophila melanogaster. BMP Rep. 2019, 52, 250-258. [CrossRef]

24. Celotto, A.M.; Palladino, M.J. Drosophila: A "model" model system to study neurodegeneration. Mol. Interv. 2005, 5, 292-303. [CrossRef] [PubMed]

25. Poddighe, S.; Bhat, K.M.; Setzu, M.D.; Solla, P.; Angioy, A.M.; Marotta, R.; Ruffilli, R.; Marrosu, F.; Liscia, A. Impaired sense of smell in a Drosophila Parkinson's model. PLoS ONE 2013, 8, e73156. [CrossRef] [PubMed]

26. Poddighe, S.; De Rose, F.; Marotta, R.; Ruffilli, R.; Fanti, M.; Secci, P.P.; Mostallino, M.C.; Setzu, M.D.; Zuncheddu, M.A.; Collu, I.; et al. Mucuna pruriens (Velvet bean) rescues motor, olfactory, mitochondrial and synaptic impairment in PINK1B9 Drosophila melanogaster genetic model of Parkinson's disease. PLoS ONE 2014, 9, e110802. [CrossRef] [PubMed]

27. Nikonova, E.V.; Xiong, Y.; Tanis, K.Q.; Dawson, V.L.; Vogel, R.L.; Finney, E.M.; Stone, D.J.; Reynolds, I.J.; Kern, J.T.; Dawson, T.M. Transcriptional responses to loss or gain of function of the leucine-rich repeat kinase 2 (LRRK2) gene uncover biological processes modulated by LRRK2 activity. Hum. Mol. Genet. 2012, 21, 163-174. [CrossRef]

28. Li, X.; Patel, J.C.; Wang, J.; Avshalumov, M.V.; Nicholson, C.; Buxbaum, J.D.; Elder, G.A.; Rice, M.E.; Yue, Z. Enhanced striatal dopamine transmission and motor performance with LRRK2 overexpression in mice is eliminated by familial Parkinson's disease mutation G2019S. J. Neurosci. 2010, 30, 1788-1797. [CrossRef]

29. Matikainen-Ankney, B.A.; Kezunovic, N.; Mesias, R.E.; Tian, Y.; Williams, F.M.; Huntley, G.W.; Benson, D.L. Altered Development of Synapse Structure and Function in Striatum Caused by Parkinson's Disease-Linked LRRK2-G2019S Mutation. J. Neurosci. 2016, 36, 7128-7141. [CrossRef]

30. Roosen, D.A.; Cookson, M.R. LRRK2 at the interface of autophagosomes, endosomes and lysosomes. Mol. Neurodegener. 2016, 11, 73. [CrossRef]

31. Carrion, M.D.P.; Marsicano, S.; Daniele, F.; Marte, A.; Pischedda, F.; Di Cairano, E.; Piovesana, E.; von Zweydorf, F.; Kremmer, E.; Gloeckner, C.J.; et al. The LRRK2 G2385R variant is a partial loss-of-function mutation that affects synaptic vesicle trafficking through altered protein interactions. Sci. Rep. 2017, 7, 5377. [CrossRef] [PubMed]

32. Tan, E.K.; Peng, R.; Wu, Y.R.; Wu, R.M.; Wu-Chou, Y.H.; Tan, L.C.; An, X.K.; Chen, C.M.; Fook-Chong, S.; $\mathrm{Lu}, \mathrm{C}$.S. LRRK2 G2385R modulates age at onset in Parkinson's disease: A multi-center pooled analysis. Am. J. Med. Genet. B Neuropsychiatr. Genet. 2009, 150B, 1022-1023. [CrossRef] [PubMed]

33. Iaccarino, C.; Crosio, C.; Vitale, C.; Sanna, G.; Carrì, M.T.; Barone, P. Apoptotic mechanisms in mutant LRRK2-mediated cell death. Hum. Mol. Genet. 2007, 16, 1319-1326. [CrossRef] [PubMed]

34. De Rose, F.; Marotta, R.; Poddighe, S.; Talani, G.; Catelani, T.; Setzu, M.D.; Solla, P.; Marrosu, F.; Sanna, E.; Kasture, S.; et al. Functional and Morphological Correlates in the Drosophila LRRK2 loss-of-function Model of Parkinson's Disease: Drug Effects of Withania somnifera (Dunal) Administration. PLoS ONE 2016, 11, e0146140. [CrossRef]

35. Lee, S.B.; Kim, W.; Lee, S.; Chung, J. Loss of LRRK2/PARK8 induces degeneration of dopaminergic neurons in Drosophila. Biochem. Biophys. Res. Commun. 2007, 358, 534-539. [CrossRef]

36. Joshi, N.; Singh, S. Updates on immunity and inflammation in Parkinson disease pathology. J. Neurosci. Res. 2018, 96, 379-390. [CrossRef]

37. Kortekaas, R.; Leenders, K.L.; van Oostrom, J.C.; Vaalburg, W.; Bart, J.; Willemsen, A.T.; Hendrikse, N.H. Blood-brain barrier dysfunction in parkinsonian midbrain in vivo. Ann. Neurol. 2005, 57, 176-179. [CrossRef]

38. Sweeney, M.D.; Sagare, A.P.; Zlokovic, B.V. Blood-brain barrier breakdown in Alzheimer disease and other neurodegenerative disorders. Nat. Rev. Neurol. 2018, 14, 133-150. [CrossRef]

39. Lawrence, H.S. The transfer in humans of delayed skin sensitivity to streptococcal $\mathrm{m}$ substance and to tuberculin with disrupted leucocytes. J. Clin. Investig. 1955, 34, 219-230. [CrossRef]

40. Viza, D.; Fudenberg, H.H.; Palareti, A.; Ablashi, D.; De Vinci, C.; Pizza, G. Transfer factor: An overlooked potential for the prevention and treatment of infectious diseases. Folia Biol. (Praha) 2013, 59, 53-67.

41. Singleton, A.B.; Farrer, M.J.; Bonifati, V. The genetics of Parkinson's disease: Progress and therapeutic implications. Mov. Disord. 2013, 28, 14-23. [CrossRef] [PubMed] 
42. Liu, Z.; Wang, X.; Yu, Y.; Li, X.; Wang, T.; Jiang, H.; Ren, Q.; Jiao, Y.; Sawa, A.; Moran, T.; et al. A Drosophila model for LRRK2-linked parkinsonism. Proc. Natl. Acad. Sci. USA 2008, 105, 2693-2698. [CrossRef] [PubMed]

43. Lee, H.; James, W.S.; Cowley, S.A. LRRK2 in peripheral and central nervous system innate immunity: Its link to Parkinson's disease. Biochem. Soc. Trans. 2017, 45, 131-139. [CrossRef] [PubMed]

44. Medzhitov, R.; Preston-Hurlburt, P.; Janeway, C.A., Jr. A human homologue of the Drosophila Toll protein signals activation of adaptive immunity. Nature 1997, 338, 394-397. [CrossRef]

45. Kouli, A.; Horne, C.B.; Williams-Gray, C.H. Toll-like receptors and their therapeutic potential in Parkinson's disease and $\alpha$-synucleinopathies. Brain Behav. Immun. 2019, 81, 41-51. [CrossRef] [PubMed]

46. Mao, Z.; Davis, R.L. Eight different types of dopaminergic neurons innervate the Drosophila mushroom body neuropil: Anatomical and physiological heterogeneity. Front. Neural Circuits 2009, 3, 5. [CrossRef] [PubMed]

47. Wang, B.; Jin, K. Current perspective on the link between neuroinflammation and neurogenesis. Metab. Brain Dis. 2015, 30, 355-365. [CrossRef]

(C) 2020 by the authors. Licensee MDPI, Basel, Switzerland. This article is an open access article distributed under the terms and conditions of the Creative Commons Attribution (CC BY) license (http://creativecommons.org/licenses/by/4.0/). 